\title{
Individuell plan i palliativ fase - ei hjelp til meistring for pårørande
}

\author{
Individuell plan som etablerast tidleg i palliativ fase, gjev pårørande håp og støtte. Dei opplever også å bli \\ sett og får avlasting av ansvar.
}

\section{FORFATTERE}

\section{Sølvi Anne Eide Lunde}

spesialsjukepleiar og høgskulelektor

Høgskulen på Vestlandet, Haugesund

\section{NøKKELORD}

Pårørende, Palliasjon, Mestring, Brukermedvirkning, Kvalitativ studie

\section{SAMMENDRAG}

Bakgrunn: Pasientar i slutten av livet ønsker ofte å vere heime, og det kan vere avgjerande korleis dei pårørande meistrar heimesituasjonen. Ein individuell plan kan sikre tverrfagleg samhandling med pasienten og dei pårørande i eit pasientforløp.

Føremål: Målet med studien var å undersøke korleis individuell plan i palliativ fase bidrog til meistring hjå pårørande.

Metode: Studien var kvalitativ. Dataa vart samla inn i to fleirstegsfokusgrupper med 12 vaksne etterlatne. Fenomenologisk-hermeneutisk metode vart brukt for å unders $\varnothing$ ke erfaringane dei hadde opplevd. Studien var godkjend av NSD.

Resultat: Informantane skildra ein krevjande kvardag i kontinuerleg beredskap. Den individuelle planen vart opplevd som ei støtte. Innhaldet og prosessen fekk fram ressursar og struktur, og det skapte meining og samanheng. Planen bidrog til at informantane opplevde håp, at dei var ein ressurs og inngjekk i samarbeidet kring pasienten. «Personsentrert omsorg» oppsummerer den heilskaplege forståinga. Temaa «lette børa - dele ansvaret» og «å vite at nokon bryr seg» er presenterte i resultatdelen, og fokusområda «pårørande treng støtte for å vere ein omsorgsressurs» og «personsentrert samarbeid» er drøfta i artikkelen.

Konklusjon: Det å ha ein individuell plan for palliativ omsorg kan bidra til meistring hjå pårørande. Tidlegare etablering av individuell plan, personsentrerte relasjonar og samhandling kan styrke brukarmedverknad og samarbeid med pårørande. Belastninga på dei pårørande kan minkast gjennom å avklare viktige spørsmål om behandling og framtid. Ved å styrke meistringa til dei pårørande legg tenesta til rette for ei betre livsavslutning i palliativ fase. Det er behov for vidare forsking på kva faktorar som verkar inn i arbeidet med individuell plan i palliativ fase og innanfor pårørandesamarbeid. 
Mange pasientar i sluttfasen av livet ønsker å vere heime, og måten dei pårørande meistrar heimesituasjonen på, kan vere avgjerande for om dette ønsket blir oppfylt (1-3). Politiske og faglege dokument understrekar at individuell plan kan sikre brukarmedverknad, tverrfagleg samhandling og synleggjering av kontaktpersonar og behova til pasienten og dei pårørande $(1,4-6)$.

Det er viktig at tenestene er samordna, heilskaplege og sikrar god behandlingskvalitet i eit pasientforløp, og at dei pårørande blir inkluderte (6-9). Artikkelen bygger på ein studie som undersøkte om individuell plan i palliativ fase bidrog til meistring for pårørande (10).

\section{«Individuell plan er ein heilskapleg plan og eit verktøy som viser tenestebehov, mål, ressursar, ansvarlege tenesteytarar, koordinator og næraste pårørande.»}

Individuell plan er ein heilskapleg plan og eit verktøy som viser tenestebehov, mål, ressursar, ansvarlege tenesteytarar, koordinator og næraste pårørande $(4,5,11)$ (tabell 1). Når pasienten over tid har behov for samordning av to eller fleire tenester, utløyser dette ein juridisk rett til individuell plan $(4,5,11,12)$. Retten er heimla i lovverk som pasient- og brukarrettslova (pbrl. ) § 2-5 og forskrifta og rettleiinga som høyrer til lova $(11,12)$.

Pasienten skal samtykke til at det blir etablert individuell plan, til ansvarsgruppa og til pårørandeinvolvering, og han skal sjølv definere kven som er pårørande, jf. pbrl. § 1-3b (4, 8, $12,13)$. Individuell plan kan reknast som ein relasjonell kontrakt der innhaldet i tenesta blir avklart i samarbeid mellom pasient, pårørande og tenesteytarar (14).

Tabell 1: Innhald i individuell plan for palliative pasientar

Konkrete moment ein individuell plan må innehalde:

- skriftleg samtykke frå pasienten

- koordinator, til dømes heimesjukepleiar

- målet til pasienten

- ansvarleg tenesteytar for kvart tenesteområde

- kontaktoversikt og ansvarsfordeling inkludert natt, kveld og helg

- avtalt oppfølging

- klare retningsliner for kor og korleis eventuell innlegging skal ordnast

(dersom open retur-omgrepet blir brukt, skal dette vere klart definert)

«Palliasjon» - lindrande behandling - er aktiv behandling og heilskapleg omsorg for pasientar med ulækjeleg sjukdom og avgrensa levetid. Målet er best mogleg livskvalitet for pasienten og dei pårørande. Pasientane har ofte eit komplekst sjukdomsbilete med hyppige endringar i helsetilstand som krev koordinert oppfølging frå helsetenesta, og dette tilseier rett til individuell plan. Samstundes er individuell plan lite brukt i palliativ fase $(1,15)$. 


\section{SøKEORD OG TIDLEGARE STUDIAR}

Litteraturs $\varnothing \mathrm{k}$ er gjort i databasar med helsefagleg innhald, som Oria, EBSCO-Cinahl, Ovid, Evidenced-Based Nursing, Cochrane, ProQuest, Norart, Idunn, Swemed. Søka vart gjorde med desse MesH-søkeorda: individual plan, individual care plan, patient care plan, caregivers, family, coping, palliative care, palliative care nursing og terminal care. Siste $\varsigma \varnothing \mathrm{k}$ vart gjort 16. mai 2017.

Det finst studiar om individuell plan (16-19), men ingen tek for seg både palliasjon og pårørandeperspektivet. Fleire norske studiar omhandlar pårørande innanfor palliasjon (20-26). Oppsummert viser studia at dei pårørande ønskjer informasjon, førebuande samtalar, st $\varnothing$ tte og tverrfaglege og tilgjengelege helsetenester for å meistre den kompliserte omsorga i kvardagen.

\section{BAKGRUNN FOR DENNE STUDIEN}

Førebuande samtalar, «advanced care planning» (ACP), er strukturerte samtalar for å avklare $\emptyset n s k e$ og behov $(2,6,21)$. Funn frå litteratursøk er brukte i drøftinga av resultat i denne studien.

Erfaringar frå pårørande i denne studien er sett i lys av teorien til Antonovsky om salutogenese (27). Den meistringsorienterte tilnærminga til Antonovsky legg vekt på faktorar som fremjar helse og bidreg til ei heilskapleg "oppleving av samanheng», OAS. OAS bygger på at det indre og ytre miljøet til den einskilde er forståeleg, handterleg og gjev meining.

Det handlar om å ha tilgjengelege ressursar og at utfordringane er verde å engasjere seg i (27). Heggen skildrar meistring som å takle krevjande og stressfylte situasjonar og bruke ressursane ein har, til å kome seg vidare på ein god måte (28, s. 65). Problemstillinga er: «Korleis kan individuell plan i palliativ fase bidra til meistring for pårørande?»

\section{METODE}

Studien var kvalitativ med ei fenomenologisk-hermeneutisk tilnærming (29). Det fenomenologiske perspektivet er dei subjektive skildringane til informantane - sjølve saka. Den abstrakte meininga, det hermeneutiske perspektivet, kjem fram gjennom analyse og tolking av dei transkriberte samtalane. Denne tilnærminga vart vald for å få fram kva erfaringar dei pårørande har med individuell plan i palliativ fase.

Forskingsdesignet var to fleirstegsfokusgrupper (30). Wibeck (31) viser til Morgan (1996) som skildrar fokusgruppe som ein forskingsteknikk der data blir samla inn gjennom gruppeinteraksjonar mellom gruppemedlemmer for å få fram kvalitative data om tema som er avgjorde av forskar. Samhandling og dynamikk mellom informantane skal opne for ny innsikt og kunnskap (32).

\section{FLEIRSTEGSFOKUSGRUPPER}

I fleirstegsfokusgrupper drøftar informantane tema og erfaringar over fleire samlingar. Dialogane skaper auka forståing gjennom nyansering og djupn i fenomena, og dei løftar erfaringane til informantane opp på eit høgare abstraksjonsnivå (30).

Rolla til moderatoren er å styre samtalen mellom informantane, ha balanse mellom innleving og distanse, lytte og fange opp meininga i det som blir formidla, følge opp med nøkkelspørsmål og sikre struktur i gruppesamtalane $(31,32)$. 
Informantane var vaksne etterlatne som bidrog i utforminga av individuell plan i palliativ fase. Deltakinga deira i studien skjedde 4 til 18 månader etter $\mathrm{d} \varnothing \mathrm{dsfallet}$ til ein vaksen familiemedlem. Dei pårørande var ektefellar, døtrer og svigerdøtrer som vart rekrutterte via helsepersonell som hadde hatt kontakt med dei i palliativ fase.

Utvalet representerte fem individuelle planar. Dei individuelle planane vart etablerte seint $\mathrm{i}$ palliativ fase - frå fire månader til ei veke før dødsfalla. Informantane var ikkje kjende for forskaren $f \varnothing r$ etter at det var gjeve samtykke til deltaking. Forskaren var moderator $i$ gruppene. Ein intervjuguide med opne tema, basert på forskingsspørsmåla, vart brukt for å skape dialog og erfaringsutveksling.

Tema som vaks fram ved analyse av data frå førre gruppesamling, vart spelte inn på neste møte. Dette skapte utdjupande drøfting av temaa. Studien er godkjend av Norsk senter for forskningsdata (NSD), tidlegare Norsk samfunnsvitenskapelig datatjeneste, og gjennomført i tråd med forskingsetiske lover og retningsliner innanfor medisinsk og helsefagleg forsking (10).

Tabell 2: Oversikt over informantane i fokusgruppene

$\begin{array}{llllll}\text { Relasjon } & \begin{array}{l}\text { Individuell plan 1 } \\ \text { / fokusgruppe 1 }\end{array} & \begin{array}{l}\text { Individuell plan 2 } \\ \text { /fokusgruppe 1 }\end{array} & \begin{array}{l}\text { Individuell plan } 3 \\ \text { /fokusgruppe 1 }\end{array} & \begin{array}{l}\text { Individuell plan 4 } \\ \text { /fokusgruppe 2 }\end{array} & \begin{array}{l}\text { Individuell plan 5 } \\ \text { /fokusgruppe 2 }\end{array} \\ \text { Ektefelle/kone } & \text { Informant nr. 1 } & \text { Informant nr. 3 } & \text { Informant nr. 6 } & \text { Informant nr. 8 } & \text { Informant nr. 10 } \\ \text { Dotter } & \text { Informant nr. 2 } & \text { Informant nr. 4 } & \text { Informant nr. 9 } & \text { Informant nr. 11, 12 } \\ \text { Svigerdotter } & & \text { Informant nr. 5 } & \text { Informant nr. 7 } & & \\ & & & & \end{array}$

\section{FENOMENOLOGISK-HERMENEUTISK ANALYSE}

Vi valde metoden til Lindseth og Norberg (2004) for fenomenologisk-hermeneutisk analyse (29). Det fenomenologiske perspektivet, dei gjennomlevde erfaringane, blir skildra av informantane i intervjua. Det hermeneutiske perspektivet, meininga i ein vidare forståingshorisont, kjem fram i tolking av intervjutekstane. Teksttolkinga byggjer på den hermeneutiske sirkelen til Ricoeur, som flyttar seg mellom forståing og forklaring (29).

Analysestega i metoden er 1) naiv forståing, 2) strukturell analyse og 3) heilskapleg forståing. Naiv forståing er ei innleiande gjennomlesing av teksten for å få fram ei heilskapleg meining der teksten «talar til oss». Deretter gjennomførte vi ein tematisk strukturell analyse med tolking av den transkriberte teksten.

Teksten blir delt i meiningsberande einingar som blir kondenserte og abstraherte for å få fram tema i lys av den naive forståinga. Til slutt blir teksten lesen og reflektert over for å få fram ei overordna forståing og kvalitetssikre samsvaret mellom naiv forståing og strukturell temaanalyse (29). Døme på strukturell temaanalyse i studien er presentert i tabell 3. 
Tabell 3: Døme på abstraksjonsprosess i analyse av temaet «lette børa - dele ansvaret»

\begin{tabular}{|c|c|c|c|}
\hline Meiningsberande einingar & Kondensering & Koding & Tema \\
\hline $\begin{array}{l}\text { [...] ein kjempekamp heile tida for at han skal ha det } \\
\text { nokolunde [...] }\end{array}$ & $\begin{array}{l}\text { Kamp for å ta } \\
\text { vare på den sjuke }\end{array}$ & $\begin{array}{l}\text { Kamp som } \\
\text { pårørande }\end{array}$ & $\begin{array}{l}\text { Omsorgs- } \\
\text { ansvar }\end{array}$ \\
\hline $\begin{array}{l}\text { [...] det var ei kjempestøtte, og eg synest både det } \\
\text { arbeidet med individuell plan - at det blei sett ned på } \\
\text { papiret at han skulle ha planar, at nokon hadde ansvaret } \\
{[\ldots . .] \text { at det var på ein måte ute av mine hender [...] at det }} \\
\text { var ein kreftsjukepleiar å vende seg til, det synest eg var } \\
\text { heilt supert, hadde oversikta over [...]noko anna når du } \\
\text { får éin eller to personar [...] }\end{array}$ & $\begin{array}{l}\text { St } \varnothing \text { tte i arbeidet } \\
\text { med individuell } \\
\text { plan } \\
\text { Fordeling av } \\
\text { ansvar } \\
\text { Oversikt } \\
\text { Fápersonar }\end{array}$ & $\begin{array}{l}\text { Støtte som } \\
\text { pårørande }\end{array}$ & $\begin{array}{l}\text { St } \varnothing \text { ttande } \\
\text { helsete- } \\
\text { neste }\end{array}$ \\
\hline
\end{tabular}

\section{RESULTAT}

Informantane skildra ein arbeidskrevjande og uoversiktleg kvardag med alvorleg sjukdom og kontinuerleg beredskap med lite $s \varnothing \mathrm{vn}$ og avlasting. Fleire opplevde det å få formalisert ein individuell plan, der koordinator, kontaktpersonar og behandlarar var nemnde, som ei støtte.

\section{«Fleire opplevde det å få formalisert ein individuell plan, der koordinator, kontaktpersonar og behandlarar var nemnde, som ei støtte.»}

Artikkelen bygger på ein studie med fleire funn: tillitsskapande relasjon, heilskapleg omsorg og behandling, arbeid for håp og verdigheit, kampen som pårørande, støtte som pårørande og dei siste timane saman (10).

I vidare analyse og litteraturs $\varnothing \mathrm{k}$ er pårørandeperspektivet gjort tydeleg, og funna er omformulerte. "Personsentrert omsorg» oppsummerer den heilskaplege forståinga, og vi presenterer temaa «lette børa - dele ansvaret» og «å vite at nokon bryr seg» i artikkelen.

\section{LETTE BØRA - DELE ANSVARET}

Det å få ein individuell plan var som «å skape orden i eit kaos», sa ein informant. Dette gav ei oppleving av tryggleik i ein utrygg situasjon.

Informant 6 sa: «[...] ein får det trygt og godt når alt anna heng i lause lufta [...]».

Å bli møtt på ein god måte var viktig for å etablere tillit til helsetenesta. Innhaldet i individuell plan synleggjorde ansvarlege fagressursar på ulike nivå i helsetenesta som kunne kontaktast. Informantane opplevde at det vart betre planlegging og heilskapleg omsorg med ei gruppe kring familien. Det å delta i planarbeidet gjorde informantane førebudde sjølv om pasientforløpet vart annleis enn planlagt.

I sluttfasen, då behovet for symptomlindring var stort, gav ei samanhengande og tverrfagleg heildøgnsteneste tryggleik fordi informantane opplevde at helsetenesta samhandla og var 
informert, i motsetnad til før den individuelle planen vart etablert.

Ein sa: «[...] dei var kjende, det var trygt [...] det var positivt sjølv om det var trist [...]».

Fastlegen er sentral og må involverast tidleg, understreka informantane. I eit «fredelegare» forløp , der relasjonen til helsetenesta var god, vart ikkje individuell plan så viktig.

Fleire informantar omtalte det å vere med på avgjerda om å avslutte livsforlengande behandling som ei belasting som prega dei i sorga etterpå. I desse avgjerdene var pasienten for sjuk til sjølv å ta dette valet. Eit tverrfagleg møte kring individuell plan, der den behandlande legen tok den endelege avgjerda, var likevel ei god støtte. Informantane meinte at spørsmål om livsforlengande behandling skulle vore avklart med den sjuke og deretter forankra i den individuelle planen.

Informantane understreka at informasjon om og etablering av individuell plan må gjerast tidleg i sjukdomsforløpet. Då har den sjuke krefter og evne til å forstå kva individuell plan er, og kan vere med i planarbeidet.

\section{Å VITE AT NOKON BRYR SEG}

Prosessen kring individuell plan var viktigare enn dokumentet. Koordinatoren vart skildra som mentoren til den sjuke - ein fagperson som prioriterte tid, inngav tillit og skapte dialog som gav styrke og støtte. Informantane skildra at dei møtte fagpersonar som kjende situasjonen til den sjuke og viste at nokon i helsetenesta «brydde seg». "At nokon bryr seg, og at det er planar om eit liv - ein plan om eit verdig liv», sa informant 12.

Pasientar og pårørande deltok i planarbeidet. Det å vere heime var ofte nedfelt som mål i individuelle planar. Det vart planlagt aktivitetar, slik at livet ikkje berre vart «ei venting på døden». Måla gav den sjuke og pårørande eit håp - ikkje om å bli frisk, men noko å strekke seg etter for å få tilbake livslyst i situasjonen.

Informant 9 sa: «[...] kva eg håpte - at vi ikkje kan forlange han blir frisk. Men at han kan klare å gå eller vere heime mest mogleg».

Støtta informantane opplevde i planprosessen, var særs viktig.

«Eg synest det var ei kjempestøtte. Og eg synest arbeidet med individuell plan - at det vart sett ned på papiret at han skulle ha planar, at nokon hadde overordna ansvaret, hadde oversikt [...]. Så då vi fekk denne planen - det var eit forferdeleg ansvar som då på ein måte var fordelt, synest eg.» Informant 2

\section{DRøFTING}

Funna viser at individuell plan var viktig for å skape meining og samanheng. For å kaste lys over korleis individuell plan kan bidra til meistring for pårørande, skal vi drøfte «pårørande treng støtte for å vere ein omsorgsressurs» og «personsentrert samarbeid».

\section{PÅRøRANDE TRENG ST ØTTE FOR Å VERE EIN OMSORGSRESSURS}

Studiar viser at pårørande treng støtte og omsorg for å vere ressurspersonar for den sjuke $(1,7,8,13,20,22,33)$. Milberg skriv at pårørande opplever uvisse og angst når dei ikkje har familiær og helsefagleg støtte tilgjengeleg i den palliative fasen (3).

Studien til Sørhus, Landmark og Grov (22) stadfestar at dei pårørande har behov for informasjon og støtte frå helsetenesta samstundes som dei opplever ansvar, meistring og meining i omsorgsoppgåvene dei utfører. I studien til Fjose og medarbeidarar (20) stadfestar 
Det var ei utfordring for informantane i vår studie å ha ein familiemedlem som var alvorleg sjuk, og samstundes vere i ein situasjon prega av uvisse og hjelpeløyse. Dei opplevde det å få ein individuell plan og vere del av ei gruppe kring den sjuke som ei avlasting av ansvar. Vidare opplevde dei at det å ha ein koordinator og individuell plan skapte orden, oversikt over aktuelle fagressursar og gav ein plan framover.

Dette reduserte uvissa deira og gjorde kvardagen meir forståeleg og handterleg. Ifølge Antonovsky kan det å få støtte i utfordrande situasjonar bidra til at ein forstår, ser meining og meistrar situasjonen (27).

\section{PÅRøRANDE I DILEMMA}

Milberg peikar på at pårørande kan oppleve konflikt mellom pasienten sitt ønske om å døy heime og eiga uvisse i om ein vil klare dette (3). Stensheim, Hjermstad og Loge viser at pårørande opplever stort ansvar, stor belasting og treng å bli sett og tekne vare på (34). Pårørandesamarbeid, samhandlande tenester og koordinator blir då viktig. I studien til Breimo, Normann, Sandvin og Thommesen gav arbeidet med individuell plan ei oppleving av tryggleik og å bli møtt og teken på alvor, og koordinatoren vart oppfatta som viktigare enn sjølve planen (4).

Rusmisbrukarar i studien til Humerfelt (16) erfarte derimot at individuell plan ikkje førte til koordinerte, heilskaplege og individuelt tilpassa tenester. Dei opplevde manglande deltaking, sviktande oppfølging og krenkande medverknad. Dette viser kor viktig relasjonen og engasjementet til koordinatoren er for å sikre brukarmedverknad i planprosessen. Studiane til Holum og Nilssen viser at ein god prosess kring individuell plan styrkar brukarmedverknad og myndiggjering $(14,18)$.

Informantar i vår studie opplevde at koordinatoren reduserte pårørandebelastinga ved å vere ei støtte og ein konfliktløysar mellom pasient og pårørande. I ettertid opplevde dei denne tida som ein styrke i sorga. Studien viser at prosessen med individuell plan - med betre informasjonsflyt, ansvarsfordeling og oversikt - skapte meining og samanheng.

\section{PERSONSENTRERT SAMARBEID}

I arbeidet med individuell plan opplevde informantane å møte fagpersonar som hadde kunnskap om situasjonen til den sjuke, og som viste at nokon i helsetenesta «brydde seg». Dette skapte håp og meining. Planarbeidet bidrog til involvering, mål å strekke seg etter og ei oppleving av å bli møtt som menneske, slik studien til Alve stadfestar (17).

\section{«Planarbeidet bidrog til involvering, mål å strekke seg etter og ei oppleving av å bli møtt som menneske.»}

Alidina og Tettero (35) viser til definisjonen til Dufault og Martocchio (1985) om håp, der håp kan synleggjere mål, strategiar og motivasjon for å nå mål. Studien viste at pasientar $\mathrm{i}$ palliativ fase treng håp for å halde oppe verdigheita si, takle stress og få betre livskvalitet. 
Håp er difor ein viktig ressurs i å meistre livstruande sjukdom. Arbeidet med individuell plan støtta opp under dette håpet, samstundes som pårørande opplevde seg mindre åleine om ansvaret i studien vår.

\section{MÅ TA VARE PÅ PÅRØRANDE}

Pårørande som Grøthe intervjua, sa det var viktig å møte profesjonelle fagpersonar med engasjement og kompetanse, som informerte og sørgde for deira behov (23). Pårørande i studien til Michael ønskte ein plan for framtida, sjølv om drøftingane vart konfronterande. Dette kunne sikre pasientengasjement, informasjon, «delt avgjerd» og pårørandestøtte (36).

Informantar i vår studie gav uttrykk for at spørsmål om livsforlengande behandling og kvar den sjuke ønskte omsorga den siste tida, skulle vore avklart med pasienten tidlegare og felt ned i ein individuell plan. Denne avklaringa hadde letta situasjonen som pårørande. Studien til Bollig, Gjengedal og Rosland (21) støttar dette, i og med at pårørande der opplevde det å ta viktige val i livsavslutninga som belastande, ettersom dei var usikre på kva ønske den sjuke hadde.

Samstundes hadde pasientane i studien, som budde på sjukeheim, tillit til å overlate desse avgjerdene til pårørande og fagpersonell. Studien konkluderer med behovet for å systematisere førebuande samtalar for å avklare framtidige ønske og på denne måten redusere pårørandebelastinga. Samstundes peikar Gawande (37) på at pasientar og pårørande opplever at dei ikkje er i stand til å ta avgjerder om eiga omsorg ved livsavgrensande sjukdom.

\section{TILPASSA INFORMASJON}

Laws, som intervjua omsorgspersonar til langtkomne kreftpasientar, stadfestar behovet for tidleg, regelmessig informasjon og planlegging av framtida gjennom førebuande samtalar. Dette reduserte angsten og uvissa til omsorgspersonane, og det auka meistringsstrategiane deira (38). Pårørande som Hunstad intervjua, ønskte at helsepersonell skulle ta initiativ til drøfting og planlegging for å nå konkrete mål, klargjere rolla til omsorgsgjevaren og sikre ei døgntilgjengeleg helseteneste og heilskapleg omsorg (24).

Bøckmann understrekar at tidleg involvering og målretta samtalar kan skape tillit og avklare behova til pårørande (13). Ifølge Brenne og Estenstad er tilgang på palliative heimetenester, sosial støtte og kompetansen til personalet viktige faktorar for å tilrettelegge for heimed $\varnothing d$

(2). Helsepersonell bør difor gje tilpassa informasjon og ta initiativ til førebuande samtalar så tidleg som mogleg for at pasienten og dei pårørande kan ta kvalifiserte avgjerder og forankre desse i ein individuell plan.

Dialogen pasient og pårørande har med koordinator, behandlande lege og helsetenesta, er grunnleggande for samhandlinga. Palliativ omsorg krev tverrfagleg samarbeid $(1,15)$. I ein studie om individuell plan i rehabiliteringsforløp var samhandling i planprosessen eit verktøy for fleksibelt samarbeid (17).

God tverrfagleg samhandling om individuell plan kan sikre informasjonsoverføring og koordinerte, målretta tenester, slik studien til Nordsveen og Andershed stadfestar (39). Individuell plan kan bidra til pårørandeinvolvering, skape struktur og synleggjere ressursar, slik at pårørande kan etablere ein handlingsberedskap i ei usikker framtid. Ifølge Antonovsky styrker dette evna til meistring (27).

\section{INDIVIDUELL PLAN AUKA MEISTRING}

Helsedirektoratet understrekar at individuell plan er viktig for brukarmedverknad i eit pasientforløp (1). Å involvere pasienten og dei pårørande i avgjerder om eiga framtid kan 


\section{«Å involvere pasienten og dei pårørande i avgjerder om eiga framtid kan bidra til auka meistring av situasjonen.»}

Breimo og medarbeidarar skriv at individuell plan krev ei haldning som er prega av gjensidig entusiasme (4). Gjensidig respekt, dialog og avgjerder som vart tekne i fellesskap, var grunnleggande for å styrke brukarmedverknad i studien til Rise (36). Ein studie av personar med kronisk sjukdom i Nederland, viste at individuell plan bidrog til eit meir personsentrert, planlagt og inkluderande samarbeid enn dersom ein ikkje hadde det (41).

Personsentrert omsorg er sentralt i sjukepleiemodellen til McCormack og McCance (42). Modellen legg vekt på individuelt tilpassa tenester, terapeutiske relasjonar og medverknad, og han bygger på verdiar som respekt og autonomi. «Kva er viktig for deg?» er sentralt i personsentrert omsorg. Ein personsentrert relasjon er grunnleggande i arbeidet med individuell plan, der sjukepleiaren ofte har ei sentral rolle som tilretteleggar og koordinator.

\section{METODEDR $\varnothing$ FTING}

Sjølv om studien vart gjennomført i 2011, før ny lov og forskrift, har funna framleis relevans (10). Funna er sett i lys av nytt lovverk og forsking. Føremålet med studien var å få innsikt og kunnskap om eit tema det er gjort lite forsking på. Fleirstegsfokusgruppedesign fungerte etter føremålet, fordi nye tema bidrog til nye refleksjonar og ei djupare forståing. Eit døme er pårørandebelastinga ved å vere med på avgjerda om å avslutte livsforlengande behandling.

Utvalet var representativt, sjølv om det hadde ei svak side ved at det berre vart rekruttert kvinner. Utvalskriteriet var at pårørande hadde vore involvert i prosessen med individuell plan i palliativ fase. Éin mann og éi kvinne trekte seg frå studien før første fokusgruppeintervju.

Eit anna svakt punkt var at éin av dei individuelle planane vart etablert berre ei veke før dødsfallet. Ifølgje Hummelvoll (30) er grupper på 5-8 deltakarar gunstig i fleirstegsfokusgrupper, og det er tilstrekkeleg med éi gruppe.

Styrken i studien er at dei to fokusgruppene, uavhengig av kvarandre, har formidla felles erfaringar som til dømes håp og verdigheit. Sjølv om utvalet er lite, kan funn i studien overførast til tilsvarande kontekstar. I retrospektive studiar kan informantar i ettertid minnast erfaringane annleis. Studien har lagt vekt på å svare på problemstillinga og forskingsspørsmåla gjennom prosessen.

\section{KONKLUSJON}

Studien viser at prosessen med individuell plan i palliativ fase kan bidra til meistring for pårørande. Informantane opplevde håp, å bli sett, avlasting av ansvar, medverknad og støtte 
i ein krevjande kvardag. Planprosessen aktiverte ressursar, etablerte struktur, skapte meining og samanheng.

Koordinator og individuell plan sikra brukarmedverknad gjennom konkretisering av pasienten og dei pårørande sine mål, roller og val i livsavslutninga. Helsetenesta stod fram som ei heil, koordinert og samanhengande teneste der informasjonsflyten mellom tenestene vart styrkt.

Likevel viser studien at rutinar for individuell plan må kvalitetssikrast. For å styrke brukarmedverknad og pårørandesamarbeid bør det etablerast individuell plan tidleg i den palliative fasen. Å avklare viktige spørsmål om behandling og framtid kan lette pårørandebelastinga.

Helsetenesta bør ta initiativ til førebuande samtalar, slik at viktige avgjerder kan forankrast i ein individuell plan. Ved at meistringa til dei pårørande blir styrkt, legg tenesta til rette for ei betre livsavslutning i palliativ fase.

Det er behov for vidare forsking på kva faktorar som bidreg i arbeidet med individuell plan i palliativ fase, og pårørandesamarbeid.

For å oppnå individuelt tilpassa, koordinerte tenester og bruk av individuell plan i eit pasientforløp er personsentrert tilnærming grunnleggande. Ei personsentrert og likeverdig tilnærming, og bruk av individuell plan krev ei haldningsendring i helsetenesta.

Ei stor takk går til informantane som delte livserfaringane sine, og helsepersonellet som bidrog til å skaffe informantar. Vidare vil eg takke Kristin Ådnøy Eriksen, Gerd Bjørke og Geir Sverre Braut for kritiske og konstruktive tilbakemeldingar på teksten undervegs i prosessen.

\section{REFERANSAR}

1. Helsedirektoratet. Nasjonalt handlingsprogram med retningslinjer innen palliasjon $\mathrm{i}$ kreftomsorgen. 2015;IS-2285.

2. Brenne AT, Estenstad B. Hjemmedød. I: Kaasa S, Loge H (red). Palliasjon: Nordisk lærebok (2. utgåve). Oslo: Gyldendal Akademisk; 2016 (s. 161-71).

3. Milberg A. Närstående vid palliativ vård. I: Strang P, Beck-Friis B (red). Palliativ medicin och vård Stockholm: Liber; 2012 (s. 144-51).

4. Breimo JP, Normann T, Sandvin JT, Thommesen H. Individuell plan. Oslo: Gyldendal Akademisk; 2015.

5. Kjellevold A. Retten til individuell plan (4. utgåve). Bergen: Fagbokforlaget; 2013.

6. Helsedirektoratet. Rapport om tilbudet til personer med behov for lindrende behandling og omsorg mot livets slutt - å skape liv til dagene. 2015;02.

7. Meld. St. 26 (2014-2015). Fremtidens primærhelsetjeneste - nærhet og helhet.

Tilgjengeleg frå: https://www.regjeringen.no/no/dokumenter/meld.-st.-26-2014-2015/id2409890/ (nedlasta 24.04.2017).

8. NOU 2011:17. Når sant skal sies om pårørendeomsorg. Fra usynlig til verdsatt og inkludert. Norges offentlige utredninger 2011;17. 
10. Lunde SAE. Individuell plan - ein plan for eit verdig liv. Masteroppgåve. Volda: Høgskulen i Volda; 2012.

11. Helse- og omsorgsdepartementet. Forskrift om habilitering og rehabilitering, individuell plan og koordinator. 2011;1256.

12. Lov av 2. juli 1999 om pasient- og brukerrettigheter (pasient- og brukerrettighetsloven). Tilgjengeleg frå: https://lovdata.no/dokument/NL/lov/1999-07-02-63 (nedlasta 26.09.2017).

13. Bøckmann K, Kjellevold A. Pårørende i helse- og omsorgstjenesten - en klinisk og juridisk innføring (2. utgåve). Bergen: Fagbokforlaget; 2015.

14. Nilssen E. Kommunal iverksetting av retten til individuell plan. Tidsskrift for velferdsforskning 2011;14(2):79-94.

15. Kaasa S, Loge JH. Palliativ medisin - en innledning. I: Kaasa S, Loge JH (red). Palliasjon nordisk lærebok (2. utgåve). Oslo: Gyldendal Akademisk; 2016 (s. 34-50).

16. Humerfelt K. Brukermedvirkning i arbeid med individuell plan. (Doktoravhandling). Trondheim: Norges teknisk-naturvitenskapelige universitet, Fakultet for samfunnsvitenskap og teknologiledelse, Institutt for sosialt arbeid og helsevitenskap; 2012.

17. Alve G, Madsen VH, Sletteb $\varnothing \AA$, Hellem E, Bruusgaard KA, Langhammer B. Individual plan in rehabilitation processes: a tool for flexible collaboration? Scandinavian Journal of Disability Research 2012;15(2):156-69.

18. Holum LC. "Individual plan" in a user-oriented and empowering perspective: A qualitative study of "individual plans" in Norwegian mental health services. Nordic Psychology 2012 03/01;64(1):44-57.

19. Sægrov S. Sjukepleiarens arbeid med individuell plan for kreftramma. Sykepleien Forskning 2015;10(1):54-61.

20. Fjose M, Eilertsen G, Kirkevold M, Grov EK. A Valuable but Demanding Time Family Life During Advanced Cancer in an Elderly Family Member. ANS 2016 Oct;39(4):358-73.

21. Bollig G, Gjengedal E, Rosland JH. They know! - Do they? A qualitative study of residents and relatives views on advance care planning, end-of-life care, and decision-making in nursing homes. Palliative Medicine 2016;30(5):456-70.

22. Sørhus GS, Landmark BT, Grov EK. Ansvarlig og avhengig - pårørendes erfaringer med forestående død i hjemmet. Klinisk sygepleje 2016;43(2):87-100.

23. Grøthe Å, Biong S, Grov EK. Acting with dedication and expertise: Relatives' experience of nurses' provision of care in a palliative unit. Palliative Supportive Care 2015

12;13(6):1547-58.

24. Hunstad I, Svindseth MF. Challenges in home-based palliative care in Norway: a qualitative study of spouses' experiences. International Journal of Palliative Nursing 2011;17(8):398-405. 
25. Stenberg U, Ruland CM, Miaskowski C. Review of the literature on the effects of caring for a patient with cancer. Psychooncology 2010;19(10):1013-25.

26. Hanssen S. Lindring av lidelse mot livets slutt - et pårørendeperspektiv. (Masteroppgåve). Göteborg: Nordiska högskolan för folkhälsovetenskap; 2006.

27. Antonovsky A. Helbredets mysterium. København: Hans Reitzel Forlag; 2000.

28. Heggen K. Rammer for meistring. I: Ekeland TJ, Heggen K (red). Meistring og myndiggjering Oslo: Gyldendal Akademisk; 2007 (s. 64-82).

29. Lindseth A, Norberg A. A phenomenological hermeneutical method for researching lived experience. Scand J Caring Sci 2004;18(2):145-53.

30. Hummelvoll JK. Multi-stage focus group interview: a central method in participatory and action-oriented research designs. Klinisk sygepleje 2010 07;24(3):4-13.

31. Wibeck V. Fokusgrupper - om fokuserade gruppintervjuer som undersökningsmetod. Lund: Studentlitteratur; 2010.

32. Malterud K. Fokusgrupper som forskningsmetode for medisin og helsefag. Oslo: Universitetsforlaget; 2012.

33. Wold KB, Rosvold E, Tønnesen S. «Jeg må bare holde ut...» Pårørendes opplevelse av å være omsorgsgiver for hjemmeboende kronisk syke pasienter - en litteraturstudie. I: Tønnesen S, Kassah B (red.). Pårørende i kommunale helse- og omsorgstjenester forpliktelser og ansvar i et utydelig landskap Oslo: Gyldendal Akademisk; 2017 (s. 52-78).

34. Stensheim H, Hjermstad MJ, Loge JH. Ivaretakelse av pårørende. I: Kaasa S, Loge JH (red). Palliasjon: Nordisk lærebok (2. utgåve). Oslo: Gyldendal Akademisk; 2016 (s. 274-86).

35. Alidina K, Tettero I. Exploring the therapeutic value of hope in palliative nursing. Palliative \& Supportive Care 2010;8(3):353-8.

36. Michael N, O'Callaghan C, Baird A, Hiscock N, Clayton J. Cancer Caregivers Advocate a Patient- and Family-Centered Approach to Advance Care Planning. Journal of Pain and Symptom Management 2014;47(6):1064-77.

37. Gawande A. Quantity and Quality of Life - Duties of care in Life-Limiting Illness. American Medical Association 2016;315(3):267-9.

38. Laws RF. Evaluating the perceptions of quality of life in informal caregivers caring for hospice patients. (Doktoravhandling). Hattiesburg: University of Southern Mississippi; 2014.

39. Nordsveen $\mathrm{H}$, Andershed B. Pasienter med kreft i palliativ fase på vei hjem - sykepleieres erfaringer med samhandling. Nordisk sygeplejeforskning 2015;5(3):239-52.

40. Wilson F, Ingleton C, Gott M, Gardiner C. Autonomy and choice in palliative care: time for a new model? J Adv Nurs 2014 05;70(5):1020-9.

41. Jansen DL, Heijmans M, Rijken M. Individual care plans for chronically ill patients within primary care in the Netherlands: Dissemination and associations with patient characteristics and patient-perceived quality of care. Scandinavian Journal of Primary Health Care 
2015;33:100-6.

42. McCormack B, McCance T. Underpinning principles of person-centred practice. In:

McCormack B, McCance T (red). Person-Centred Practice in Nursing and Health Care: Theory and Practice Chichester, West Sussex, United Kingdom: WILEY Blackwell; 2017 (s. 13-35). 